\title{
Solo efforts hamper tsunami warning system
}

\section{David Cyranoski, Kobe}

A plan to set up a tsunami warning system for the Indian Ocean - and eventually the whole world - received enthusiastic support in Kobe, Japan, last week. But observers cautioned that the job is being made harder by a lack of coordination and data sharing between countries.

At the United Nations World Conference on Disaster Reduction, scientists and policymakers from around the globe were quick to pledge national contributions to the concept.

So far, the most concrete plans for hardware to support a warning system have been laid out by India. It has pledged to spend US\$30 million from February to expand its network of tide gauges, seismic stations and 'tsunameters' - ocean-bottom monitors that can detect changes in pressure from a mere one-centimetre-high wave.

"We have a long coast line and a great number of natural disasters besides tsunamis. We want this system very badly," says S. K. Subramanian, head of the India Meteorological Department in New Delhi. "When we issue a warning, it will be based on the Indian system."

In the meantime, Germany plans to stations in and around Indonesia. And the United States has announced a plan to spend $\$ 37.5$ million expanding its Pacific warning system (see 'A system that works ... if people listen', below).

Coordination is necessary both to ensure spend some US $\$ 40$ million adding ten 'new generation' tsunameters and 40 seismic

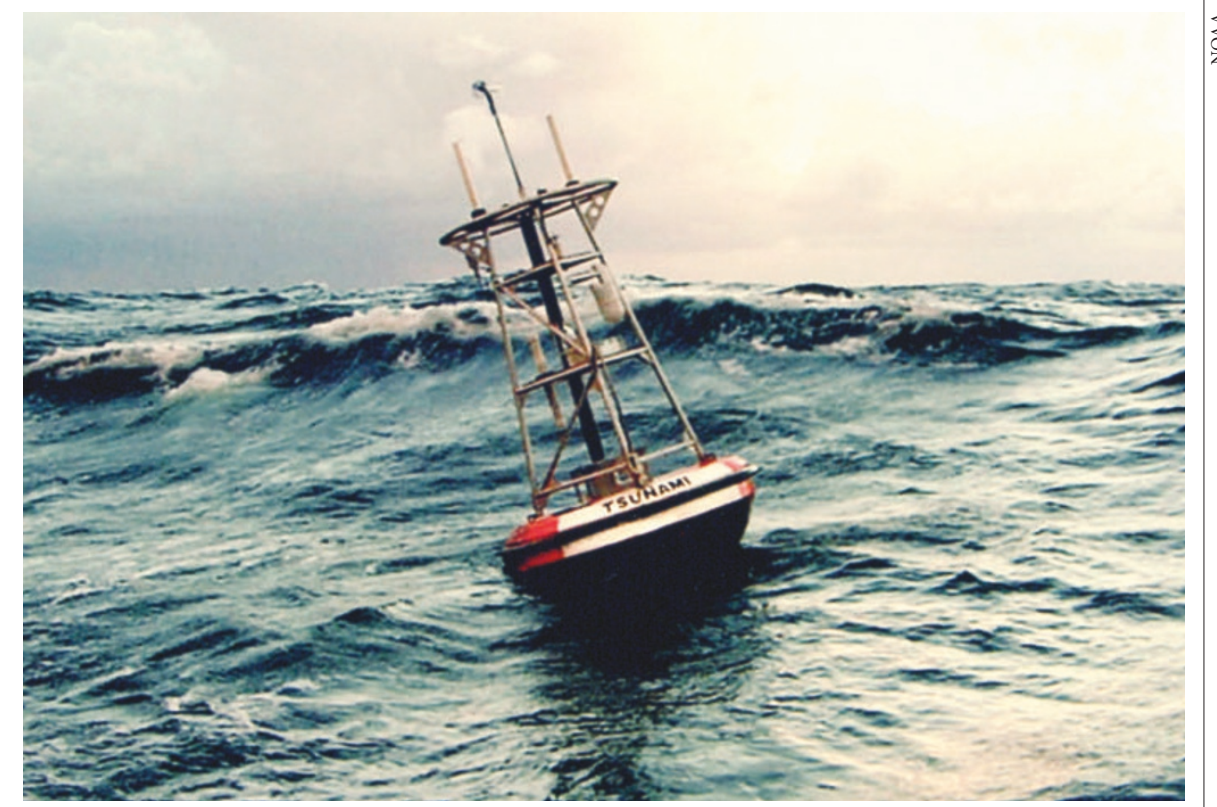

Chasing the waves: deep-ocean buoys could be marshalled for a global tsunami warning system.

that resources are not wasted and to avoid potential confusion from conflicting warnings, says Laura Kong, director of the International Tsunami Information Center in Honolulu, Hawaii. "Instruments in the Indian Ocean are currently owned and used by a number of countries. We must ensure coordination and sharing of data," she says.

But so far coordination has been seen as lacking. One US representative, for example, noted at the conference that he had learned more about Germany's technical plans by

\section{A system that works ... if people listen}

As representatives from around the world gathered in Kobe, Japan, to discuss earthquakes and tsunamis, a magnitude 6.8 earthquake hit the sea some $200 \mathrm{~km}$ southeast of Tokyo. Within minutes, Japan's warning system had kicked in, broadcasting a message on television screens across the country saying that the quake would not cause dangerous waves for those on land, but that there was limited danger for those in the water.

Most tsunami experts agree that nowhere is more prepared for tsunamis than Japan, which gets hit by damaging waves roughly once every seven years. "It's the best-prepared nation both in terms of hardware and general awareness," says Laura Kong, director of the International Tsunami Information Center in Honolulu, Hawaii.

Earthquakes are detected within two minutes by seismic monitors all around the country. Seismic information is quickly fed into a computer simulation that contains 100,000 precalculated outcomes for earthquakes of various magnitudes and depths at 4,000 different locations. One minute later, one of six regional centres, staffed around the clock, can disseminate warnings by TV or radio.

For tsunamis triggered by earthquakes farther away, Japan is helped by the Pacific Tsunami Warning Center in Hawaii - a US system consisting of six seafloor pressure sensors which triggers alarms for Pacific nations. This is the only oceanic tsunami warning system currently in place. It has won plaudits for detecting tsunamis and evaluating the danger it was successfully used to cancel a tsunami warning and prevent an evacuation in Hawaii in November 2003, for example. But it isn't perfect: three of its six buoys have been out of commission since at least September 2004; one has been down for 18 months. The United States plans to upgrade the system to 38 buoys across the Pacific, Atlantic and Caribbean by mid-2007.

But despite all this investment, Pacific nations still face the problem of human error. Tohoku University tsunami specialist Fumihiko Imamura notes that even when tsunami warnings are issued in Japan, people go to the beach to watch.

David Cyranoski talking to the press than from meetings with German representatives themselves.

UNESCO's Intergovernmental Oceanographic Commission will host two technical meetings in Paris in March to discuss how to move forward in light of the many initiatives that are emerging - although this will be after some of the efforts, including India's, have begun.

India says that its system, which should be up and running in 2007, will offer warnings to the entire region. But Kong argues that without one internationally designated centre to coordinate the information, confusion could arise. "What will countries in the region do when they get different estimates and different warnings?" she asks.

India has also been criticized for not sharing tide-gauge data that are essential for understanding the ocean's dynamics, and for refusing access to some researchers keen to study the country and its islands in the wake of the earthquake.

James Whitcomb of the US National Science Foundation's Earth-science division noted at the meeting that easier access to India's seismic data could have cut the time it took for scientists to realize the full scale of the 26 December earthquake - which was originally estimated at 8.0 , but was later upgraded to 9.0. Seismic data from north of the source area - from India or China, for example - would have helped, said Whitcomb.

Indian representatives pointed out that their data are available on a website (www.imd.ernet.in) within half an hour of an event, but Whitcomb said that real-time data, as offered by many other countries, would be preferable for global warnings. 